\title{
Macrosomia is a risk factor for incident maternal chronic kidney disease
}

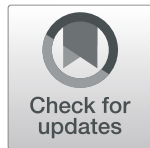

Mohammad Vahidi ${ }^{1 \dagger}$, Samaneh Asgari ${ }^{1 \dagger}$, Maryam Tohidi $^{{ }^{*}}$, Fereidoun Azizi ${ }^{2}$ and Farzad Hadaegh ${ }^{1}$

\begin{abstract}
Background: Gestational diabetes mellitus (GDM) and macrosomia are associated with several adverse outcomes including diabetes mellitus and cardiovascular diseases, however, the relationship between GDM/macrosomia with incident chronic kidney disease (CKD) is a matter of debate. The purpose of this study was to examine the association between the history of macrosomia with or without GDM and incident maternal CKD.

Methods: The study population includes 2669 women aged 18-50 years without known diabetes mellitus and CKD from participants of the Tehran Lipid and Glucose Study. The study population was categorized into 3 groups; group 1: GDM/macrosomia and without diabetes mellitus $(n=204)$, group 2: newly diagnosed incident diabetes mellitus (NDM) in the presence or abcence of GDM/Macrosomia $(n=113)$, and, group 3: the reference group including women without prior history of GDM/macrosomia and free of NDM $(n=2352)$. CKD was defined as an estimated glomerular filtration rate (eGFR) $<60 \mathrm{ml} / \mathrm{min} / 1.73 \mathrm{~m}^{2}$. Multivariable Cox proportional hazard regression adjusted for baseline values of age, body mass index, waist circumference, parity numbers, smoking, educational level, gestational hypertension, eGFR, systolic and diastolic blood pressures (SBP and DBP, respectively), antihypertensive medication, and family history of diabetes mellitus was applied for data analyses.

Results: During a median follow-up of 11.9 years, 613 incident CKD cases were identified. The multivariable hazard ratio (HR) and 95\% confidence interval (Cl) on GDM/macrosomia group was [1.32 (1.02-1.72)]; the risk was more prominent among non-hypertensive women [1.41 (1.07-1.85); P for interaction: 0.046]. Moreover, the history of macrosomia alone also showed a significant risk [1.36 (1.04-1.78)]; however, history of GDM alone did not have a significant risk [0.92 (0.342.46)]. Age, current smoking, eGFR, and SBP remained as independent risk factors for incident CKD.

Conclusions: A history of GDM/macrosomia or macrosomia alone, independent of subsequent diabetes mellitus was associated with significant risk for incident maternal CKD. Pregnancy may provide a unique situation to identify high-risk women at risk for CKD that could benefit from regular monitoring of kidney function and providing risk modifying strategies.
\end{abstract}

Keywords: Chronic kidney disease, Gestational diabetes mellitus, Macrosomia

\footnotetext{
*Correspondence: tohidi@endocrine.ac.ir

${ }^{\dagger}$ Mohammad Vahidi and Samaneh Asgari contributed equally to this work as co-first authors.

'Prevention of Metabolic Disorders Research Center, Research Institute for Endocrine Sciences Shahid Beheshti University of Medical Sciences, Tehran, Iran

Full list of author information is available at the end of the article
}

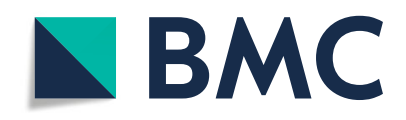

(- The Author(s). 2021 Open Access This article is licensed under a Creative Commons Attribution 4.0 International License, which permits use, sharing, adaptation, distribution and reproduction in any medium or format, as long as you give appropriate credit to the original author(s) and the source, provide a link to the Creative Commons licence, and indicate if changes were made. The images or other third party material in this article are included in the article's Creative Commons licence, unless indicated otherwise in a credit line to the material. If material is not included in the article's Creative Commons licence and your intended use is not permitted by statutory regulation or exceeds the permitted use, you will need to obtain permission directly from the copyright holder. To view a copy of this licence, visit http://creativecommons.org/licenses/by/4.0/. The Creative Commons Public Domain Dedication waiver (http://creativecommons.org/publicdomain/zero/1.0/) applies to the data made available in this article, unless otherwise stated in a credit line to the data. 


\section{Background}

Chronic kidney disease (CKD) is an issue known as a considerable cause to increase morbidity and mortality with a prevalence of about $13.4 \%$ across the world [1]; the prevalence rate for CKD in Iran compared to the global rate is higher with a rate of $18.9 \%$ [2]. Moreover, we previously reported that more than $2 \%$ of the Iranian population develops CKD each year [3]. Impaired glucose tolerance, high blood pressure, and high body-mass index (BMI) have been associated with a higher risk of CKD development [4]. Tackling CKD and its risk factors could be deemed an obligation due to its insidious nature and significant burden on global health.

Gestational diabetes mellitus (GDM) is one of the most common complications of pregnancy that is a glucose intolerance status with onset or first diagnosis during pregnancy [5]. A global perspective study in 2016 reported that the Middle East and North Africa (MENA) region had the highest rank in the prevalence of GDM [6]. Results from a meta-analysis estimated the prevalence of GDM in Iran to be around $3.41 \%$ with a range of 1.3 to $18.6 \%$ [7]. GDM is increasing in prevalence among the Iranian population in tandem with the dramatic increase in the prevalence of obesity, physical inactivity, and glucose intolerance status including both prediabetes and type 2 diabetes mellitus (T2DM) [8-10]. Although most women with GDM will be normoglycemic after delivery [11], a history of GDM is known to increase the risk of subsequent T2DM, hypertension, metabolic syndrome, cardiovascular diseases (CVD), and endothelial dysfunction [12-18].

Macrosomia is defined as birth weight $>4000 \mathrm{~g}$ by the American College of Obstetricians and Gynecologists and has a prevalence of about $9 \%$ worldwide [19, 20]. It is reported that GDM and pre-GDM were associated with a higher prevalence of macrosomia [21] which is likely to increase the risk of future maternal T2DM [22, 23].

The question that whether GDM can independently increase the risk of CKD was poorly addressed in limited studies with inconsistent results [24-30]; most of them were based on a cross-sectional or retrospective design. A recent meta-analysis reported that no significant association between GDM and CKD was observed. However, black women with GDM had a higher risk of developing CKD [31]. Furthermore, to the best of our knowledge, there is no study investigating the impact of macrosomia on maternal CKD incidence.

Regarding the high burden of both GDM and CKD on the MENA region $[4,6]$ and relatively high prevalence of macrosomia [20], we aimed to study the relationship between macrosomia with or without GDM and incident CKD in the context of the oldest cohort of the region called the Tehran Lipid and Glucose Study (TLGS).

\section{Methods}

The TLGS is a population-based longitudinal study carried out on individuals aged $\geq 3$ years living in the urban area of metropolitan city of Tehran. This study aimed to determine the prevalence and incidence of noncommunicable diseases and their related risk factors.

The TLGS recruitment was done in two phases (the first, 1999-2001 and the second, 2002-2005). Data collection is planned to continue for at least 20 years at approximately 3-year intervals (i.e. third phase: 20052008, fourth phase: 2009-2011, fifth phase: 2012-2015). The design and registration of the TLGS have been previously described [32].

\section{Study population}

As shown in Fig. 1, of total 5,491 women aged 18-50 years (phase $1=4459$ from; phase $2=1032$ ), we excluded single women $(n=1161)$, women who did not experience pregnancy $(n=555)$, and had no live birth $(n=49)$ at the time of study recruitment. We also excluded individuals on glucose-lowering medication $(n=72)$ or prevalent CKD cases $(n=169)$. Of the remaining 3485 women, we also excluded participants with missing data for covariates including BMI, serum creatinine, fasting plasma glucose (FPG), 2-h post-load plasma glucose (2hPLG), smoking status, systolic and diastolic blood pressures (SBP and DBP, respectively) considering the overlapped features $(n=302)$. Finally, after further exclusion of participants with missing follow-up data on serum creatinine $(n=514)$, our study sample included 2669 women who were followed until March 20, 2015. All participants signed informed written consent before being enrolled in the study. The study was reviewed and approved by the ethics committee of Shahid Beheshti University of Medical Sciences (Ethics approval reference number: IR.SBMU.MSP.REC.1399.175).

\section{Clinical, anthropometric, and laboratory measurements}

Clinical, anthropometric, and laboratory data were collected according to the protocols of the TLGS [32]. Trained interviewers completed a detailed, pretested questionnaire for each participant. The questionnaire consisted of information regarding demographic data, marital status, education, smoking habits, medication history, family history of diabetes mellitus (FH-DM), and history of underlying comorbidities including hypertension, CKD, T2DM, GDM, and macrosomic baby delivery. Anthropometric variables consisted of weight, height, and waist circumference (WC). Qualified physicians measured height and weight in standing upright position with ordinary alignment of the shoulders while subjects were without shoes and dressed lightly using a tape meter and digital electronic weighing scale (Seca 707, Seca Corp., Hanover, MD, USA; range $0.1-150 \mathrm{Kg}$, 


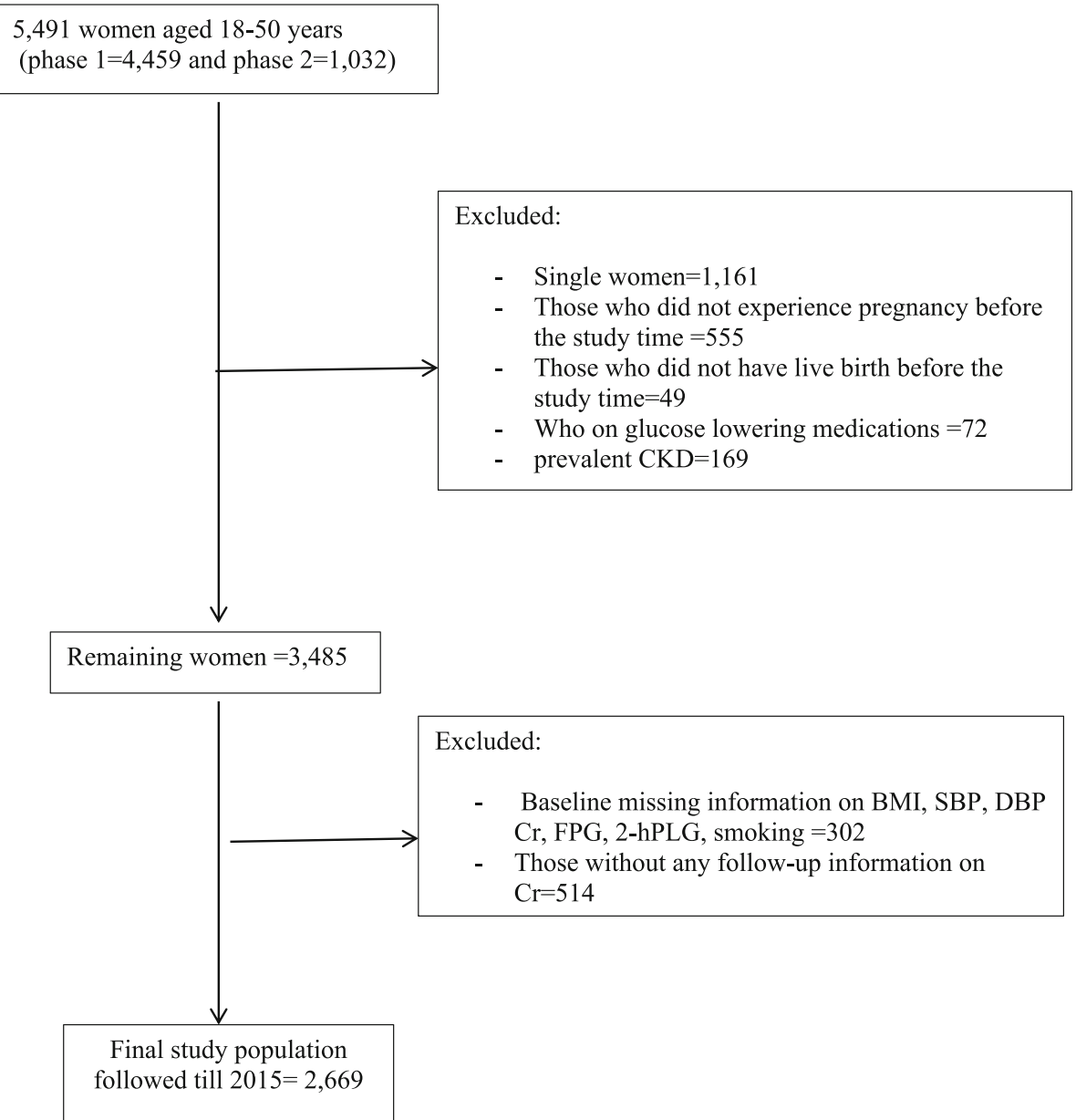

Fig. 1 Flowchart of the study population. Abbreviations: CKD, chronic kidney disease; BMI, body mass index; SBP, systolic blood pressure; DBP, diastolic blood pressure; FPG, fasting plasma glucose; 2-hPLG, 2-h post load plasma glucose; $C r$ : creatinine

recorded to the nearest $0.1 \mathrm{Kg}$ ), respectively. BMI was calculated by dividing body weight $(\mathrm{Kg})$ by squared height $\left(\mathrm{m}^{2}\right)$. WC was measured at the umbilical level.

The participants rested for $15 \mathrm{~min}$ in the sitting position to be prepared for blood pressure assessment. Skilled physicians measured blood pressure on two separate examinations with at least a $30 \mathrm{~s}$ interval from the right arm using a standardized mercury sphygmomanometer (calibrated by Iranian Institute of Standards and Industrial Researches). We regarded the average of the two measurements as the individual's blood pressure.

A venous blood sample was collected from all participants between 7:00 and 9:00 am after 12-14 $\mathrm{h}$ of overnight fasting. The sample was then centrifuged within 30-45 min of collection. Oral glucose tolerance test was conducted using an $82.5 \mathrm{~g}$ glucose monohydrate solution (equivalent to $75 \mathrm{~g}$ anhydrous glucose) for all of the population not on glucose-lowering medication. Two hours after glucose ingestion a second blood sample is collected.
FPG and 2-hPLG were assayed using enzymatic colorimetric glucose oxidase method; both intra- and interassay coefficient of variations (CVs) were less than $2.2 \%$. Total cholesterol (TC) was assayed using the enzymatic colorimetric method with cholesterol esterase- cholesterol oxidase. For high density lipoprotein-cholesterol (HDL-C) measurement, precipitation of the apolipoprotein B containing lipoproteins with phosphotungstic acid was first done. For both TC and HDL-C, intra- and inter-assay CVs were 0.5 and $2 \%$ respectively. Serum creatinine levels were assayed by kinetic colorimetric Jaffe method. The sensitivity of the assay was $18 \mathrm{mmol} / \mathrm{L}(0.2 \mathrm{mg} / \mathrm{dL})$ with measuring range of $18-1330 \mathrm{mmol} / \mathrm{L}(0.2-15 \mathrm{mg} / \mathrm{dL})$. Reference intervals according to manufacturer's recommendation were $80-115 \mathrm{mmol} / \mathrm{L} \quad(0.9-1.3 \mathrm{mg} / \mathrm{dL})$ and $53-97 \mathrm{mmol} / \mathrm{L} \quad(0.6-1.1 \mathrm{mg} / \mathrm{dL})$ in men and women, respectively. Both intra and inter-assay CVs were less than $3.1 \%$ in both baseline and follow-up phases. All biochemical assays were performed using commercial kits (Pars Azmoon Inc., Tehran, Iran) by 
a Selectra 2 auto-analyzer (Vital Scientific, Spankeren, The Netherlands). Assay performance was monitored after every 25 tests using lyophilized serum controls in normal and pathologic ranges and all samples were analyzed when internal quality control met the standard acceptance criteria.

\section{Definition of terms}

According to the Kidney Disease Outcome Quality Initiative guidelines, CKD is defined as kidney damage or glomerular filtration rate $($ GFR $)<60 \mathrm{ml} / \mathrm{min} / 1.73 \mathrm{~m}^{2}$ present for more than 3 months which translates to CKD stage 3-5 [33]. For this study, estimated GFR (eGFR) was calculated using a commonly abbreviated prediction equation, provided by Chronic Kidney Disease Epidemiology Collaboration (CKD-EPI) study as follows:

EPI: eGFR $=141 \times \min \left(\mathrm{S}_{\mathrm{cr}} / \kappa, 1\right)^{\alpha} \times \max \left(\mathrm{S}_{\mathrm{cr}} / \mathrm{\kappa}, 1\right)^{-1.209} \times$ $0.993^{\text {age }} \times 1.018$ (if female) $\times 1.159$ (if black).

In this equation, serum creatinine $\left(\mathrm{S}_{\mathrm{cr}}\right)$ was measured in $\mathrm{mg} / \mathrm{dL}$ and age in years. $\mathrm{k}$ is 0.7 and 0.9 for men and women, respectively, $\alpha$ is -0.329 and -0.411 for men and women; min indicates the minimum $S_{\mathrm{cr}} / \kappa$ or 1 , and max indicates the maximum $S_{\mathrm{cr}} / \kappa$ or 1 . Estimated GFR is also expressed as $\mathrm{mL} / \mathrm{min} / 1.73 \mathrm{~m}^{2}$ [34].

A positive FH-DM was considered if any firstdegree relatives of the participant had T2DM. Parity was defined as pregnancies longer than 20 weeks leading to either live birth or stillbirth. Hypertension was defined as either taking anti-hypertensive drug treatment or SBP $>140 \mathrm{mmHg}$ or DBP $>90 \mathrm{mmHg}$. A person with a BMI of $30 \mathrm{Kg} / \mathrm{m}^{2}$ or more was considered obese. According to the first report of the Iranian National Committee of Obesity central adiposity was defined as $W C \geq 90 \mathrm{~cm}$ for both men and women [35]. Hypercholesterolemia was defined as TC $\geq 5.18$ $\mathrm{mmol} / \mathrm{L}$ or using lipid-lowering medications. Low $\mathrm{HDL}-\mathrm{C}$ was defined as $\mathrm{HDL}-\mathrm{C}<1.036 \mathrm{mmol} / \mathrm{L}$ for men and $<1.295 \mathrm{mmol} / \mathrm{L}$ for women. Participants were stratified either into married or widowed/divorced groups based on their marital status. Smoking habits were categorized into former, current, and non smokers. A current smoker was considered a person who smokes cigarettes, pipe, or hookah daily or occasionally; those who didn't currently smoke with a previous history of smoking were defined as former smokers, and those without any history of smoking were categorized as never smoker (as the reference group). Educational level was categorized into 3 groups of $<6$ years, $6-12$ years, and $>12$ years of education.

\section{Definition of exposure groups}

In the current study, we categorized the study population into three groups: group 1; GDM/macrosomia, including participants with a self-reported history of macrosomia (birth weight $>4000 \mathrm{~g}$ ) or GDM and without T2DM, group 2 ; incident cases of newly diagnosed T2DM (NDM), consisted of participants who had FPG $\geq 7 \mathrm{mmol} / \mathrm{L}$ or 2 -hPLG $\geq 11.1 \mathrm{mmol} / \mathrm{L}$ in the presence or abcence of GDM/ Macrosomia, and, group 3; the reference group including women without prior history of GDM/macrosomia and free of NDM (no GDM/macrosomia and no NDM).

\section{Statistical analysis}

Continuous and categorical variables were reported as mean (standard deviation-SD) or frequencies (\%) as appropriate. Comparison of baseline characteristics of the three groups of participants including women with a history of GDM/macrosomia, women with incident NDM, and women without a history of GDM/macrosomia and NDM (reference group) was performed using the ANOVA test for continuous variables and Chi-square test for categorical variables. The crude incidence rate (95\% confidence interval- CI) was calculated by dividing the number of new cases of CKD by person-years at risk. Cox proportional hazard regression was used to examine the relationship between GDM/macrosomia and incident NDM categories with incident CKD in 3 models; model 1, unadjusted; model 2, adjusted only for baseline age and model 3, adjusted for baseline age, and other potential confounders according to our previous study [3] including BMI, WC, number of parities, smoking status, educational level, gestational hypertension, eGFR, SBP, DBP, anti-hypertensive medication, and FH-DM.

A Kaplan-Meier survival curve was used to estimate the cumulative incidence of CKD. To show the robustness of our findings, we tested the interaction between the different status of general obesity, central adiposity, hypercholesterolemia, lowHDL-C, and hypertension with our main exposures (i.e. GDM/macrosomia and NDM) with incident CKD in age-adjusted analysis, using the likelihood ratio test [4]. Schoenfeld's global test of residuals was used to check the proportionality assumption of the multivariable Cox regression and no interference was observed.

The level of significance was set at $<0.05$ for all statistical analyses. All statistical analyses were done using STATA statistical package version 14 SE (StataCorp, TX, USA).

\section{Results}

Of all 2669 participants, 204 women $(7.64 \%)$ had a history of GDM/macrosomia, 113 subjects (4.23\%) were incident cases of NDM and 2352 participants (88.13\%) were neither with T2DM nor had a history of GDM/ macrosomia. The baseline characteristics of these three groups are described in Table 1 . The mean age (SD) and BMI of all participants at baseline were 36.2 (7.3) years 
Table 1 Baseline characteristics of the participants based on different categories of GDM/macrosomia, with and without diabetes

\begin{tabular}{|c|c|c|c|c|c|}
\hline Variables & $\begin{array}{l}\text { Total } \\
(n=2669)\end{array}$ & $\begin{array}{l}\text { No diabetes } \\
(n=2352)\end{array}$ & $\begin{array}{l}\text { GDM/macrosomia } \\
(n=204)\end{array}$ & $\begin{array}{l}\text { NDM } \\
(n=113)\end{array}$ & $P$ value \\
\hline Age, years & $36.2(7.3)$ & $35.6(7.2)$ & $39.5(6.5)$ & $42.5(5.3)$ & $<0.001$ \\
\hline $\mathrm{BMI}\left(\mathrm{Kg} / \mathrm{m}^{2}\right)$ & $27.7(4.6)$ & $27.4(4.5)$ & $30.1(4.5)$ & $30.3(4.9)$ & $<0.001$ \\
\hline$W C(\mathrm{~cm})$ & $87(11.5)$ & $86(11.1)$ & $93.6(11.1)$ & $95.8(11.9)$ & $<0.001$ \\
\hline $\mathrm{SBP}(\mathrm{mmHg})$ & $112.2(13.7)$ & $111.3(13.2)$ & $114.4(14.1)$ & $125.3(14.9)$ & $<0.001$ \\
\hline $\mathrm{DBP}(\mathrm{mmHg})$ & $75.7(9.7)$ & $75.3(9.5)$ & $77.3(10.1)$ & $82.4(9.4)$ & $<0.001$ \\
\hline FPG (mmol/L) & $4.99(0.80)$ & $4.88(0.49)$ & $5.06(0.56)$ & $7.21(2.04)$ & $<0.001$ \\
\hline 2-hPLG (mmol/L) & $6.29(2.37)$ & $5.90(1.45)$ & $6.33(1.56)$ & $14.4(3.94)$ & $<0.001$ \\
\hline eGFR $\left(\mathrm{ml} / \mathrm{min} / 1.73 \mathrm{~m}^{2}\right)$ & $78.8(10.8)$ & $79.3(10.9)$ & $75.7(9.7)$ & $74.4(8.6)$ & $<0.001$ \\
\hline $\mathrm{TC}(\mathrm{mmol} / \mathrm{L})$ & $5.15(1.03)$ & $5.10(1.03)$ & $5.29(0.94)$ & $5.74(1.07)$ & $<0.001$ \\
\hline $\mathrm{HDL}-\mathrm{C}(\mathrm{mmol} / \mathrm{L})$ & $1.14(0.29)$ & $1.15(0.29)$ & $1.10(0.28)$ & $1.04(0.25)$ & $<0.001$ \\
\hline Parity & $2.6(1.4)$ & $2.5(1.3)$ & $3.2(1.4)$ & $3.6(1.5)$ & $<0.001$ \\
\hline Marital status, n (\%) & & & & & 0.658 \\
\hline - Married & 2569 (96.3) & $2226(96.3)$ & $196(96.1)$ & $107(94.7)$ & \\
\hline - Widow/divorced & $100(3.7)$ & $86(3.7)$ & $8(3.9)$ & $6(5.3)$ & \\
\hline Smoking status, n (\%) & & & & & 0.62 \\
\hline - Never & $2530(94.8)$ & $2232(94.9)$ & $192(94.1)$ & $106(93.8)$ & \\
\hline - Former & $21(0.8)$ & $20(0.9)$ & $1(0.5)$ & $0(0)$ & \\
\hline - Current & $118(4.4)$ & $100(4.3)$ & $11(5.4)$ & $7(6.2)$ & \\
\hline Education, n (\%) & & & & & $<0.001$ \\
\hline$-\quad<6$ years & $629(23.6)$ & $516(21.9)$ & $61(29.9)$ & $52(46)$ & \\
\hline - 6-12 years & $1786(66.9)$ & $1597(67.9)$ & $132(64.7)$ & $57(50.4)$ & \\
\hline$-\quad \geq 12$ years & $254(9.5)$ & $239(10.2)$ & $11(5.4)$ & $4(3.5)$ & \\
\hline Obesity, n (\%) & $750(28.1)$ & $596(25.3)$ & $101(49.5)$ & $53(46.9)$ & $<0.001$ \\
\hline Hypertension, n (\%) & $292(10.9)$ & $234(9.9)$ & $27(13.2)$ & $31(27.4)$ & $<0.001$ \\
\hline FH-DM, n (\%) & 769 (28.8) & $655(27.8)$ & $71(34.8)$ & $43(38.1)$ & 0.009 \\
\hline Anti-hypertensive medication, n (\%) & $69(2.59)$ & $56(2.38)$ & $5(2.45)$ & $8(7.08)$ & 0.009 \\
\hline Lipid-lowering medication, n (\%) & $34(1.27)$ & $25(1.06)$ & $5(2.45)$ & $4(3.54)$ & 0.021 \\
\hline Incident CKD, n (\%) & $613(23.0)$ & $510(21.7)$ & 69 (33.8) & $34(30.1)$ & $<0.001$ \\
\hline
\end{tabular}

Abbreviations: NDM: newly diagnosed diabetes; GDM, gestational diabetes mellitus; BMI, body mass index; WC, waist circumference; SBP, systolic blood pressure; DBP, diastolic blood pressure; FPG, fasting plasma glucose; 2-hPLG, 2-h post load plasma glucose; eGFR, estimated glomerular filtration rate; TC, total cholesterol; $\mathrm{HDL}-\mathrm{C}$, high density lipoprotein-cholesterol; FH-DM, family history of diabetes mellitus; CKD, chronic kidney disease

Values are shown as Mean (SD) and number (\%) for continuous and categorical variables, respectively

and $27.7(4.6) \mathrm{Kg} / \mathrm{m}^{2}$, respectively. Generally, incident cases of NDM showed a less favorable situation for all baseline characteristics compared to other groups, excluding incident CKD and obesity, which were more prevalent in the GDM/macrosomia group (all $P$ values $<0.05$ ). We observed no significant difference in smoking status and marital status between study groups. Moreover, the frequency of incident CKD cases among GDM/macrosomia were higher compared with incident cases of NDM and T2DMfree individuals ( 33.8 vs. 30.1 vs. $21.7 \%$, respectively).

During a median follow-up (interquartile range) of 11.9 years (8.3-13.2), 613 incident cases of CKD were identified with the corresponding incidence rate of 21.6 (95\% CI: 20-23.4) per 1000 person-year. Figure 2 shows the Kaplan-Meier survival curve for the cumulative CKD incidence in the three study groups (log-rank test $P$ value $<0.001$ ).

Crud, age and multivariable adjusted hazard ratio (HR) of GDM/macrosomia and incident NDM with incident CKD is shown in Table 2. Accordingly, only GDM/ macrosomia showed 33\% significant risk for incident CKD in the age-adjusted analysis [HR: 1.33 (95\% CI: 1.03-1.71)]; the risk still remained significant after further adjustment for potential risk factors [HR: 1.32 (95\% CI: $1.02-1.72), P=0.032$ ]. In the multivariable analysis, aging [HR: 1.06 (95\% CI: 1.04-1.08)], current smoker [HR: 1.42 (95\% CI: 1.00-1.99)], level of eGFR [HR: 0.91 (95\% CI: 0.90-0.92)] and SBP [HR: 1.01 (95\% CI: 1.00- 


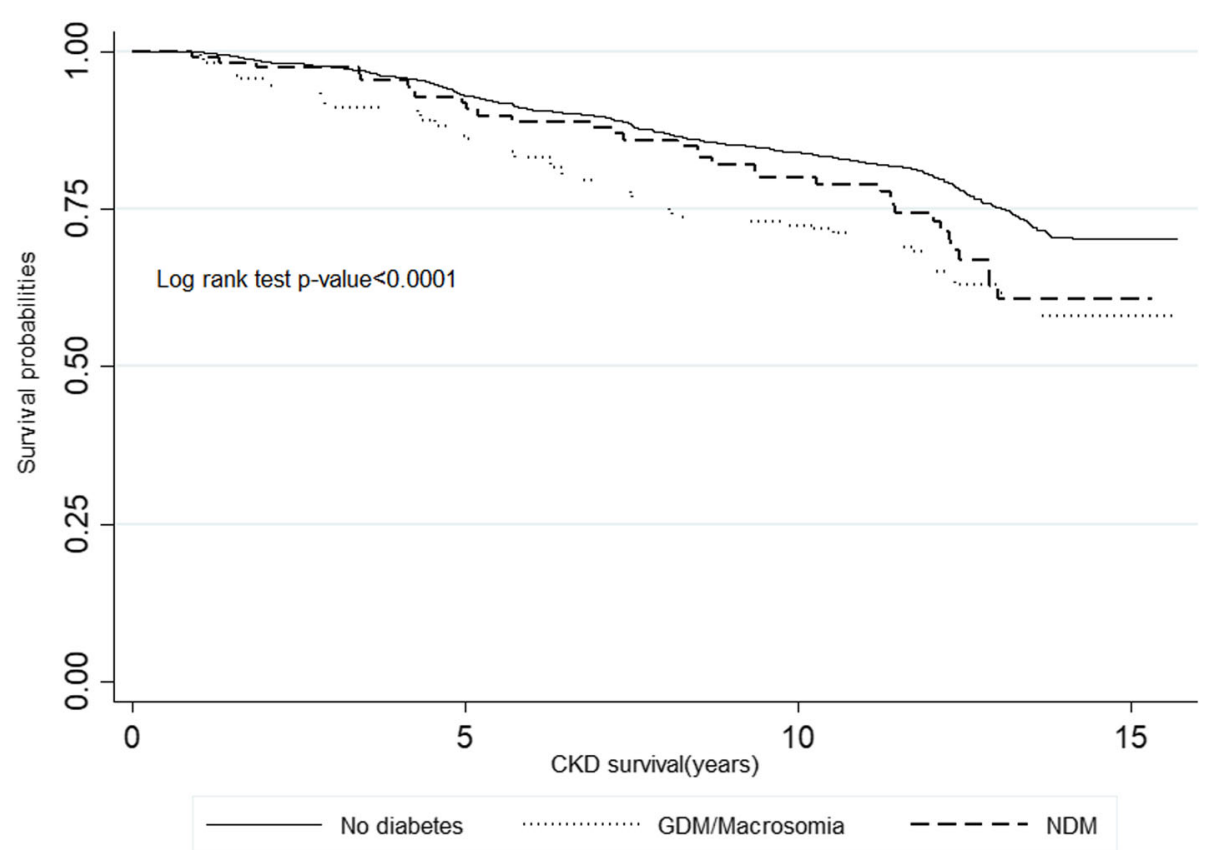

Fig. 2 Kaplan-Meier survival curve for cumulative incident CKD of different categories of GDM/macrosomia, with and without diabetes. Abbreviations: CKD, chronic kidney disease; GDM, gestational diabetes mellitus; NDM: newly diagnosed type 2 diabetes mellitus

1.02)] also remained independent risk factors. The results remained essentially unchanged when we replaced the definition of GDM/macrosomia with a history of macrosomia alone as shown in Table 3. Accordingly, having a history of macrosomia was associated with a higher risk for incident CKD of 36\% [HR: 1.36 (95\% CI: 1.04-1.78)]. However, when we replaced the definition of GDM/macrosomia with a history of GDM alone no association was found between GDM and incident CKD [HR: 0.92 (95\% CI: 0.34-2.46)] (Table 4). In stratified analyses as shown in Fig. 3, we did not find a significant interaction between different study groups and general obesity $(P=0.59)$, central adiposity $(P=0.14)$, hypercholesterolemia $(P=0.22)$, and low HDL-C $(P=0.13)$. However, the data analysis showed a significant interaction between hypertension status and different study groups $(P=0.046)$. Hence, only among the non-hypertensive population, GDM/macrosomia group showed a significant risk for incident CKD [HR: 1.41 (95\% CI: 1.07-1.85)]. Moreover, unexpectedly we found that the incident NDM group among the hypertensive population had a lower risk for CKD; however, considering only 6 events in this group, the effect size is unstable [HR: 0.42 (95\% CI: 0.18-0.97)].

As a sensitivity analysis, the inverse probability weighting of the multinomial propensity score [36] was used to balance characteristics among three exposure groups (i.e. those without GDM/macrosomia and diabetes, with GDM/Macrosomia, and with undiagnosed diabetes). The analysis adjusted for baseline age, BMI, WC, number of parities, smoking status, educational level, gestational hypertension, eGFR, SBP, DBP, anti-hypertensive medication, and FH-DM. The result remained unchanged, the HRs (95\% CI) for GDM/macrosomia and NDM groups were [HR: 1.34 (95\% CI: 1.03-1.74)] and 1.05 (95\% CI: 0.75-1.50)], respectively (data not shown).

\section{Discussion}

For more than a decade of follow-ups among women aged 18-50 years in Tehran, we found that a history of GDM/macrosomia was associated with more than $30 \%$ higher risk of CKD, independent of a large set of important potential confounders including age, general obesity, central adiposity, parity, educational level, gestational hypertension, smoking status, FH-DM, SBP, DBP, using anti-hypertensive medication, and eGFR. This correlation also applied to women with a history of macrosomia alone. Moreover, we also found that in women with a history of GDM/macrosomia, non-hypertensive participants had a higher risk of CKD incidence compared to hypertensive participants.

The results of other studies examining the relationship between GDM and CKD are incompatible for comparison with each other, due to the different approaches applied for diagnosis of GDM, different sample sizes, various study designs (cross-sectional, retrospective, or prospective), the selection method of participants (hospital or population-based study), and number and type of confounders. Moreover, all of the studies in this field were confined to the United States (US), European 
Table 2 Hazard ratios of different categories of GDM/macrosomia, with and without diabetes for incident CKD

\begin{tabular}{|c|c|c|c|c|c|c|}
\hline \multirow[t]{2}{*}{ Variables } & \multicolumn{2}{|l|}{ Model 1} & \multicolumn{2}{|l|}{ Model 2} & \multicolumn{2}{|l|}{ Model 3} \\
\hline & HR (95\% Cl) & $P$ value & HR (95\% Cl) & $P$ value & HR (95\% Cl) & $P$ value \\
\hline \multicolumn{7}{|l|}{ Study groups } \\
\hline - $\quad$ No diabetes & Reference & & Reference & & Reference & \\
\hline - GDM/macrosomia & $1.78(1.39-2.30)$ & $<0.001$ & $1.33(1.03-1.71)$ & 0.029 & $1.32(1.02-1.72)$ & 0.032 \\
\hline - NDM & $1.45(1.02-2.05)$ & 0.037 & $0.80(0.56-1.39)$ & 0.22 & $0.74(0.52-1.07)$ & 0.109 \\
\hline Age, years & & & $1.10(1.09-1.11)$ & $<0.001$ & $1.06(1.04-1.08)$ & $<0.001$ \\
\hline BMI $\left(\mathrm{Kg} / \mathrm{m}^{2}\right)$ & - & - & - & - & $1.01(0.98-1.05)$ & 0.43 \\
\hline WC (cm) & - & - & - & - & $0.99(0.98-1.00)$ & 0.38 \\
\hline Parity & - & - & - & - & $0.98(0.92-1.06)$ & 0.68 \\
\hline \multicolumn{7}{|l|}{ Smoking status } \\
\hline - Never & - & - & - & - & Reference & \\
\hline - Former & & & & & $0.87(0.36-2.10)$ & 0.75 \\
\hline - Current smoker & - & - & - & - & $1.42(1.00-1.99)$ & 0.048 \\
\hline \multicolumn{7}{|l|}{ Education } \\
\hline - $\quad<6$ years & - & - & - & - & Reference & \\
\hline - 6-12 years & - & - & - & - & $1.20(0.98-1.47)$ & 0.077 \\
\hline$-\quad \geq 12$ years & - & - & - & - & $1.18(0.84-1.66)$ & 0.34 \\
\hline Gestational hypertension & - & - & - & - & $0.97(0.92-1.03)$ & 0.37 \\
\hline $\operatorname{eGFR}\left(\mathrm{ml} / \mathrm{min} / 1.73 \mathrm{~m}^{2}\right)$ & - & - & - & - & $0.91(0.90-0.92)$ & $<0.001$ \\
\hline $\mathrm{SBP}(\mathrm{mmHg})$ & - & - & - & - & $1.01(1.00-1.02)$ & 0.043 \\
\hline $\mathrm{DBP}(\mathrm{mmHg})$ & - & - & - & - & $0.99(0.98-1.005)$ & 0.26 \\
\hline Anti-hypertensive medication & - & - & - & - & $0.99(0.63-1.53)$ & 0.95 \\
\hline FH-DM & - & - & - & - & $1.01(0.85-1.20)$ & 0.88 \\
\hline
\end{tabular}

Model 1: Study groups (unadjusted model)

Model 2: adjusted for baseline age

Model 3: adjusted for baseline age, BMI, WC, number of parities, smoking status, educational level, gestational hypertension, eGFR, SBP, DBP, anti-hypertensive medication, and FH-DM

Abbreviations: NDM: Newly diagnosed type 2 diabetes mellitus; GDM, gestational diabetes mellitus; CKD, chronic kidney disease; $\mathrm{HR}$, hazard ratio; $\mathrm{Cl}$, confidence interval; BMI, body mass index; WC, waist circumference; eGFR, estimated glomerular filtration rate; SBP, systolic blood pressure; DBP, diastolic blood pressure; FHDM, family history of diabetes mellitus

and Israeli women, and no population-based study examined this relationship in the MENA region [24-30].

The question regarding the relationship between GDM and subsequent impaired kidney function was first addressed by Friedman et al. [24] in a cross-sectional study of 72 Israeli women with a history of GDM, and as a result, a higher risk of microalbuminuria was observed. In another cross-sectional study with larger sample size, US women with GDM alone had similar odds of CKD stages 1-2 (odds ratio: 1.54) comparable with women with overt diabetes (odds ratio: 1.68) [26]. These findings were supported by another retrospective hospital-based cohort study in Israel which observed that GDM was a significant risk factor for long-term renal morbidity [27]. To the best of our knowledge, only 3 prospective cohorts have examined the relationship between GDM and incident CKD. The first study was conducted in 2015 with a sample size of 320 Canadian women of whom 100 cases had a history of GDM, confirmed by oral glucose tolerance test, and after 3 years of follow-up, they reported that current glucose intolerance, but not GDM, was associated with microalbuminuria. Importantly, in contrast to previous studies, the authors considered current glucose intolerance and eGFR as important confounders in their data analysis [28]. In the Coronary Artery Risk Development in Young Adults (CARDIA) Study, the presence of the self-reported GDM among black women, was associated with incident CKD, mainly attributable to albuminuria. This association did not change after adjustment for a large set of pre-pregnancy risk factors for both GDM and CKD including eGFR and fasting glucose concentrations [30]. In a prospective study of 607 Danish women with GDM with a mean follow-up of 13 years, a higher rate of increased eGFR levels was seen compared to the control group, indicating an early stage of renal damage. Moreover, the authors also showed that renal damage defined as increased urine albumin-creatinine ratio (UACR), was 
Table 3 Hazard ratios of different categories of macrosomia, with and without diabetes for incident CKD

\begin{tabular}{|c|c|c|c|c|c|c|}
\hline & \multicolumn{2}{|l|}{ Model 1} & \multicolumn{2}{|l|}{ Model 2} & \multicolumn{2}{|l|}{ Model 3} \\
\hline & $\mathrm{HR}(95 \% \mathrm{Cl})$ & $P$ value & HR (95\% CI) & $P$ value & HR $(95 \% \mathrm{Cl})$ & $P$ value \\
\hline \multicolumn{7}{|l|}{ Study groups (n) } \\
\hline - $\quad$ No diabetes (2380) & Reference & & Reference & & Reference & \\
\hline - $\quad$ Macrosomia (176) & $2.0(1.54-2.59)$ & $<0.001$ & $1.37(1.06-1.78)$ & 0.017 & $1.36(1.04-1.78)$ & 0.023 \\
\hline - $\quad$ NDM (113) & $1.45(1.03-2.05)$ & 0.035 & $0.80(0.56-1.43)$ & 0.22 & $0.74(0.52-1.07)$ & 0.111 \\
\hline Age, years & - & - & $1.10(1.09-1.11)$ & $<0.001$ & $1.06(1.04-1.08)$ & $<0.001$ \\
\hline BMI $\left(\mathrm{Kg} / \mathrm{m}^{2}\right)$ & - & - & - & - & $1.01(0.98-1.05)$ & 0.43 \\
\hline WC (cm) & & & & & $0.99(0.98-1.01)$ & 0.38 \\
\hline Parity & & & & & $0.98(0.92-1.06)$ & 0.68 \\
\hline \multicolumn{7}{|l|}{ Smoking status } \\
\hline - Never & - & - & - & - & Reference & \\
\hline - Former & & & & & $0.87(0.36-2.10)$ & 0.75 \\
\hline - Current smoker & - & - & - & - & $1.42(1.00-2.00)$ & $<0.001$ \\
\hline \multicolumn{7}{|l|}{ Education } \\
\hline - $\quad<6$ years & - & - & - & - & Reference & \\
\hline - 6-12 years & - & - & - & - & $1.20(0.98-1.47)$ & 0.078 \\
\hline - $\quad \geq 12$ years & - & - & - & - & $1.18(0.84-1.66)$ & 0.34 \\
\hline Gestational hypertension & - & - & - & - & $0.97(0.92-1.03)$ & 0.37 \\
\hline $\operatorname{eGFR}\left(\mathrm{ml} / \mathrm{min} / 1.73 \mathrm{~m}^{2}\right)$ & - & - & - & - & $0.91(0.90-0.92)$ & $<0.001$ \\
\hline $\mathrm{SBP}(\mathrm{mmHg})$ & - & - & - & - & $1.01(1.00-1.02)$ & 0.042 \\
\hline $\mathrm{DBP}(\mathrm{mmHg})$ & - & - & - & - & $0.99(0.98-1.01)$ & 0.26 \\
\hline Anti-hypertensive medication & - & - & - & - & $0.99(0.64-1.53)$ & 0.96 \\
\hline FH-DM & - & - & - & - & $1.02(0.85-1.21)$ & 0.90 \\
\hline
\end{tabular}

Model 1: Study groups (unadjusted model)

Model 2: adjusted for baseline age

Model 3: adjusted for baseline age, BMI, WC, number of parities, smoking status, educational level, gestational hypertension, eGFR, SBP, DBP, anti-hypertensive medication, and FH-DM

Abbreviations: NDM: newly diagnosed type 2 diabetes mellitus; CKD, chronic kidney disease; $\mathrm{HR}$, hazard ratio; $\mathrm{Cl}$, confidence interval; $\mathrm{n}$, number; $\mathrm{BMI}$, body mass index; WC, waist circumference; eGFR, estimated glomerular filtration rate; SBP, systolic blood pressure; DBP, diastolic blood pressure; FH-DM, family history of diabetes mellitus

limited to GDM cases with subsequent development of T2DM [29]. In a recent meta-analysis including 2 studies, it was shown that history of GDM was associated with a $20 \%$ increased risk of CKD, the values which did not reach the significance level [risk ratio: 1.19 (95\% CI: 0.72-1.97), I²: 66\%] [31].

Interestingly, in the current study, we showed for the first time that a history of macrosomia alone in the absence of a history of self-reported GDM was also significantly associated with incident CKD. The association between the history of macrosomia and the development of T2DM and CVD had been previously reported [22, 23, 37]. Studies have also shown a strong association between pre-pregnancy maternal obesity, decreased insulin sensitivity, and increased insulin resistance with the delivery of macrosomic babies [38, 39]. Hence, the significant relationship between the history of macrosomia and incident CKD among Iranian women might be attributable to the high prevalence of pre-pregnancy maternal obesity and metabolic syndrome, two of the main risk factors for incident CKD, among Iranian women [4, 10, 40].

Although the precise mechanism underlying the higher risk of CKD among GDM cases observed in some studies is unknown, several potential mechanisms may explain the relationship. Interleukin-6, C-reactive protein, and plasminogen activator inhibitor-1 which are inflammatory factors that can anticipate future CVD and CKD [41-44] are significantly higher in women with a history of GDM compared to those with no prior history $[45,46]$. Moreover, a lower plasma adiponectin concentration, an antiinflammatory factor, has been observed in women with GDM history [47]. Vascular endothelial dysfunction is associated with incident CKD [48], which is more prevalent in GDM women compared to the control group, in terms of increased wall stiffness [49], increased peripheral vascular resistance [46], impaired endothelium-dependent vasodilatation [50], and impaired acetylcholine-induced skin vasodilatation [49, 51]. Subclinical inflammation and 
Table 4 Hazard ratios basof different categories of GDM, with and without diabetes for incident CKD

\begin{tabular}{|c|c|c|c|c|c|c|}
\hline & Model 1 & & Model 2 & & Model 3 & \\
\hline & HR $(95 \% \mathrm{Cl})$ & $P$ value & HR $(95 \% \mathrm{Cl})$ & $P$ value & HR $(95 \% \mathrm{Cl})$ & $P$ value \\
\hline Study groups (n) & & & & & & \\
\hline - $\quad$ No diabetes (2527) & Reference & & Reference & & Reference & \\
\hline - $\quad$ Macrosomia (29) & $0.61(0.23-1.66)$ & 0.34 & $0.83(0.31-2.21)$ & 0.71 & $0.92(0.34-2.46)$ & 0.86 \\
\hline - $\quad \operatorname{NDM}(113)$ & $1.36(0.96-1.93)$ & 0.08 & $0.77(0.54-1.10)$ & 0.15 & $0.71(0.50-1.02)$ & 0.06 \\
\hline Age, years & - & - & 1.10(1.09-1.12) & $<0.001$ & $1.06(1.04-1.08)$ & $<0.001$ \\
\hline $\mathrm{BMI}\left(\mathrm{Kg} / \mathrm{m}^{2}\right)$ & - & - & - & - & $1.01(0.98-1.05)$ & 0.4 \\
\hline$W C(\mathrm{~cm})$ & & & & & $0.99(0.98-1.01)$ & 0.48 \\
\hline Parity & & & & & $0.99(0.92-1.06)$ & 0.77 \\
\hline Smoking status & & & & & & \\
\hline - Never & - & - & - & - & Reference & \\
\hline - Former & & & & & $0.85(0.35-2.05)$ & 0.72 \\
\hline - Current smoker & - & - & - & - & $1.40(0.99-2.0)$ & 0.05 \\
\hline Education & & & & & & \\
\hline - $\quad<6$ years & - & - & - & - & Reference & \\
\hline - 6-12 years & - & - & - & - & $1.20(0.98-1.47)$ & 0.08 \\
\hline - $\quad \geq 12$ years & - & - & - & - & $1.18(0.84-1.66)$ & 0.34 \\
\hline Gestational hypertension & - & - & - & - & $0.97(0.92-1.03)$ & 0.3 \\
\hline eGFR $\left(\mathrm{ml} / \mathrm{min} / 1.73 \mathrm{~m}^{2}\right)$ & - & - & - & - & $0.91(0.90-0.92)$ & $<0.001$ \\
\hline $\mathrm{SBP}(\mathrm{mmHg})$ & - & - & - & - & $1.01(1.00-1.02)$ & 0.039 \\
\hline $\mathrm{DBP}(\mathrm{mmHg})$ & - & - & - & - & $0.99(0.98-1.01)$ & 0.24 \\
\hline Anti-hypertensive medication & - & - & - & - & $0.97(0.63-1.51)$ & 0.9 \\
\hline $\mathrm{FH}-\mathrm{DM}$ & - & - & - & - & $1.01(0.85-1.21)$ & 0.87 \\
\hline
\end{tabular}

Model 1: Study groups (unadjusted model)

Model 2: adjusted for baseline age

Model 3: adjusted for baseline age, BMI, WC, number of parities, smoking status, educational level, gestational hypertension, eGFR, SBP, DBP, anti-hypertensive medication, and FH-DM

Abbreviations: NDM: newly diagnosed type 2 diabetes mellitus; GDM: gestational diabetes mellitus; CKD, chronic kidney disease; $\mathrm{HR}$, hazard ratio; $\mathrm{Cl}$, confidence interval; $n$, number; BMI, body mass index; WC, waist circumference; eGFR, estimated glomerular filtration rate; SBP, systolic blood pressure; DBP, diastolic blood pressure; FH-DM, family history of diabetes mellitus

vascular endothelial dysfunction in GDM, in the absence of overt T2DM, may suggest a possible link between GDM and subsequent CKD.

The strength of this study lies in the long-term followup of participants in a population-based study with a high burden of CVD risk factors and CKD [2, 52]. Moreover, the higher risk of CKD was also shown in the presence of well-known CKD risk factors including age, smoking status, eGFR, and SBP [4]. Importantly we also considered incident T2DM as another important confounder in our data analysis. Furthermore, most confounders were precisely measured using standardized protocols rather than relying on self-report data. We also for the first time showed the significant relationship between the history of macrosomia and incident CKD.

Our study has important limitations that should be considered. First, GDM was defined based on self-reported data; an approach applied in multiple other studies [30]. Second, we defined CKD according to a single estimate of eGFR and accepted the possibility of overestimation of CKD cases. Estimated GFR shows intraindividual biological variability and preferably needs a second creatinine measurement to accurately represent kidney function. The use of successive eGFR, had they been accessible, would have most likely reduced the incidence of CKD stage 3-4 but might not have affected the relationship between the 3 study groups (GDM/ macrosomia, incident NDM, and reference group) and CKD. Despite this, most of the population-based studies focusing on CKD as the outcome used single serum creatinine measurements [29]. Furthermore, a recently published systematic review and meta-analyses aimed to assess the predictive role of obesity, overweight, and BMI on the risk of new-onset CKD, showed the association between obesity and low eGFR did not affect by the number of eGFR measurements [53]. Third, we did not validate the CKD-EPI equation in a local population, and this could also lead to an overestimation of the incidence of 


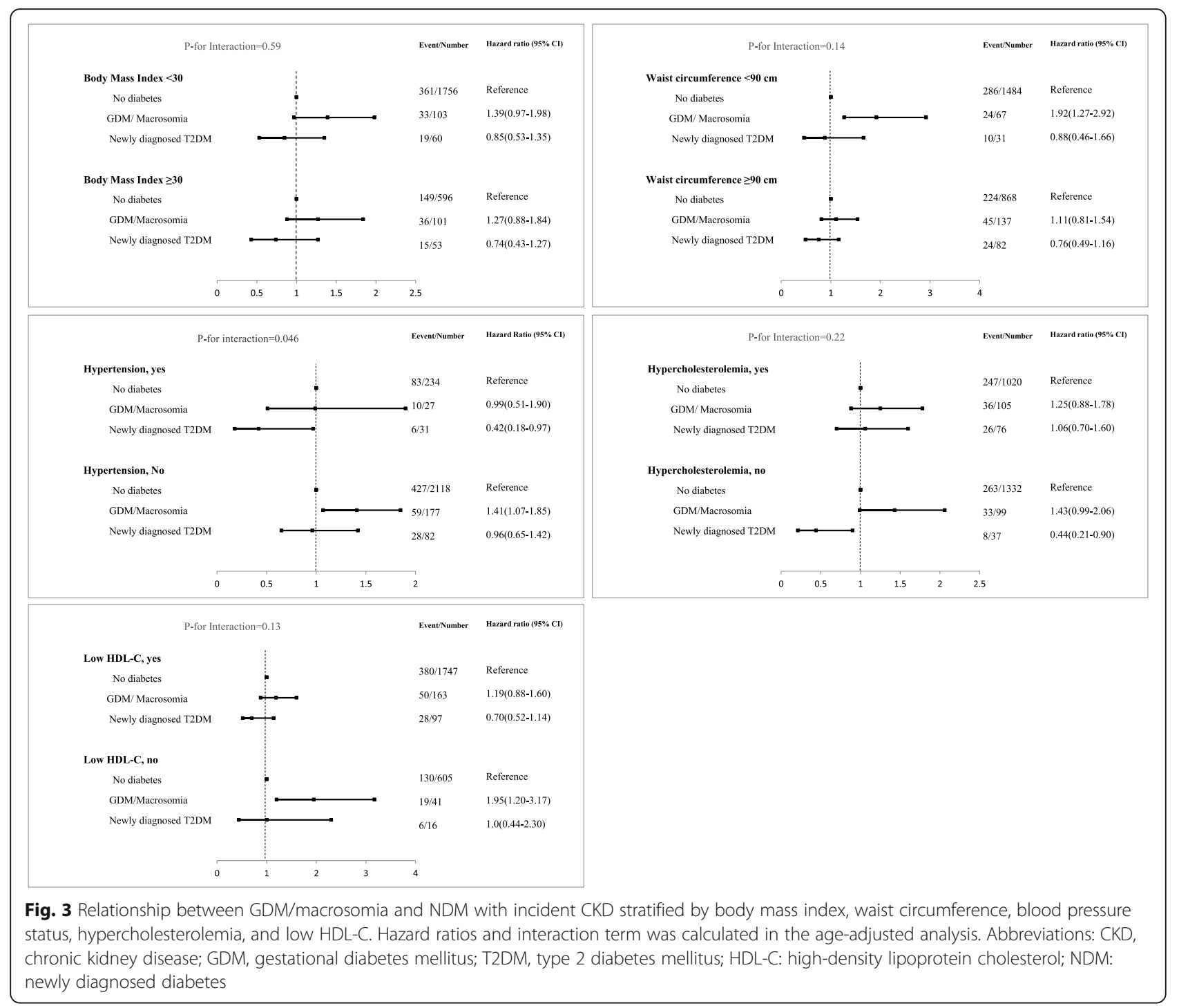

CKD. Fourth, the definition of CKD was built only upon eGFR criteria, since no valid data for urine protein excretion were available in the TLGS. Fifth, this study was conducted in the metropolitan city of Tehran, hence other studies particularly in the rural area should examine this association.

\section{Conclusions}

We concluded that Iranian women with a history of GDM/macrosomia or even macrosomia alone are at higher risk for subsequent $C K D$, independent of traditional CKD risk factors as well as incident T2DM. Given the high incidence of CKD among the Iranian population [3], pregnancy may provide a unique situation to identify high-risk women at risk for CKD that could benefit from regular monitoring of kidney function and providing risk modifying strategies.

\section{Abbreviations}

TLGS: Tehran Lipid and Glucose Study; CARDIA: Coronary Artery Risk Development in Young Adults; MENA: Middle East and North Africa; BMI: Body mass index; TC: Total cholesterol; WC: Waist circumference; SBP: Systolic blood pressure; DBP: Diastolic blood pressure; HDL-C: Highdensity lipoprotein cholesterol; 2-hPLG: 2-h post-load plasma glucose; FPG: Fasting plasma glucose; Cr: Creatinine; GFR: Glomerular filtration rate; eGFR: estimated glomerular filtration rate; T2DM: Type 2 diabetes mellitus; NDM: Newly diagnosed type 2 diabetes mellitus; CKD: Chronic kidney disease; CVD: Cardiovascular diseases; GDM: Gestational diabetes mellitus; FHDM: Family history of diabetes mellitus; Cl: Confidence interval;

CV: Coefficient of variations; HR: Hazard ratio; IQR: Interquartile Range;

SD: Standard deviation

\section{Acknowledgments}

We are grateful to all TLGS participants and their families who spent their precious time and participated in this research program. We are also thankful for the tireless efforts of the research team members. This manuscript is the result of the MD thesis of Dr. Mohammad Vahidi.

\section{Authors' contributions}

MT, FH, and FA raised the presented idea. MV, SA, MT, and FH designed the study. SA conducted the analyses. MV, SA, and MT developed the draft of 
the manuscript. All authors contributed to the writing of the paper, and have read and approved the final manuscript.

\section{Funding}

This study was initially supported in part by grant No. 121 from the National Research Council of the Islamic Republic of Iran and then by grant No 25327 from the Shahid Beheshti University of Medical Sciences.

\section{Availability of data and materials}

The data supporting this study is available through the corresponding author upon reasonable request.

\section{Declarations}

\section{Ethics approval and consent to participate}

All participants signed informed written consent before being enrolled in the study. The study was reviewed and approved by the ethics committee of Shahid Beheshti University of Medical Sciences (Ethics approval reference number: IR.SBMU.MSP.REC.1399.175). All procedures were performed according to appropriate guidelines and regulations.

\section{Consent for publication}

Not applicable.

\section{Competing interests}

The authors declare that they have no competing interests.

\section{Author details}

${ }^{1}$ Prevention of Metabolic Disorders Research Center, Research Institute for Endocrine Sciences Shahid Beheshti University of Medical Sciences, Tehran, Iran. ${ }^{2}$ Endocrine Research Center, Research Institute for Endocrine Sciences, Shahid Beheshti University of Medical Sciences, Tehran, Iran.

Received: 10 November 2020 Accepted: 3 March 2021

\section{Published online: 16 March 2021}

\section{References}

1. Hill NR, Fatoba ST, Oke JL, Hirst JA, O'Callaghan CA, Lasserson DS, et al. Global prevalence of chronic kidney disease-a systematic review and metaanalysis. PLoS One. 2016;11(7):e0158765.

2. Hosseinpanah F, Kasraei F, Nassiri AA, Azizi F. High prevalence of chronic kidney disease in Iran: a large population-based study. BMC Public Health. 2009;9(1):44.

3. Tohidi M, Hasheminia M, Mohebi R, Khalili D, Hosseinpanah F, Yazdani B, et al. Incidence of chronic kidney disease and its risk factors, results of over 10 year follow up in an Iranian cohort. PLoS One. 2012;7(9):e45304.

4. Bikbov B, Purcell CA, Levey AS, Smith M, Abdoli A, Abebe M, et al. Global, regional, and national burden of chronic kidney disease, 1990-2017: a systematic analysis for the global burden of disease study 2017. Lancet. 2020;395(10225):709-33.

5. Serlin DC, Lash RW. Diagnosis and management of gestational diabetes mellitus. Am Fam Physician. 2009;80(1):57-62.

6. Zhu Y, Zhang C. Prevalence of gestational diabetes and risk of progression to type 2 diabetes: a global perspective. Current diabetes reports. 2016;16(1):7.

7. Jafari-Shobeiri M, Ghojazadeh M, Azami-Aghdash S, Naghavi-Behzad M, Piri R, Pourali-Akbar $Y$, et al. Prevalence and risk factors of gestational diabetes in Iran: a systematic review and meta-analysis. Iran J Public Health. 2015; 44(8):1036-44

8. Hadaegh F, Derakhshan A, Zafari N, Khalili D, Mirbolouk M, Saadat N, et al. Pre-diabetes tsunami: incidence rates and risk factors of prediabetes and its different phenotypes over 9 years of follow-up. Diabet Med. 2017;34(1):69-78.

9. Koohpayehzadeh J, Etemad K, Abbasi M, Meysamie A, Sheikhbahaei S, Asgari F, et al. Gender-specific changes in physical activity pattern in Iran: national surveillance of risk factors of non-communicable diseases (20072011). International journal of public health. 2014;59(2):231-41.

10. Hosseinpanah F, Mirbolouk M, Mossadeghkhah A, Barzin M, Serahati S, Delshad $\mathrm{H}$, et al. Incidence and potential risk factors of obesity among Tehranian adults. Prev Med. 2016;82:99-104.
11. Lobner K, Knopff A, Baumgarten A, Mollenhauer U, Marienfeld S, GarridoFranco $\mathrm{M}$, et al. Predictors of postpartum diabetes in women with gestational diabetes mellitus. Diabetes. 2006;55(3):792-7.

12. Albareda M, Caballero A, Badell G, Rodriguez-Espinosa J, Ordonez-Llanos J, de Leiva A, et al. Metabolic syndrome at follow-up in women with and without gestational diabetes mellitus in index pregnancy. Metabolism. 2005; 54(8):1115-21.

13. Carpenter MW. Gestational diabetes, pregnancy hypertension, and late vascular disease. Diabetes Care. 2007;30(Suppl 2):S246-50.

14. Pirkola J, Pouta A, Bloigu A, Miettola S, Hartikainen AL, Jarvelin MR, et al. Prepregnancy overweight and gestational diabetes as determinants of subsequent diabetes and hypertension after 20-year follow-up. J Clin Endocrinol Metab. 2010;95(2):772-8.

15. Bentley-Lewis R, Powe C, Ankers E, Wenger J, Ecker J, Thadhani R. Effect of race/ethnicity on hypertension risk subsequent to gestational diabetes mellitus. Am J Cardiol. 2014;113(8):1364-70.

16. Kaul P, Savu A, Nerenberg KA, Donovan LE, Chik CL, Ryan EA, et al. Impact of gestational diabetes mellitus and high maternal weight on the development of diabetes, hypertension and cardiovascular disease: a population-level analysis. Diabet Med. 2015;32(2):164-73.

17. Goueslard K, Cottenet J, Mariet AS, Giroud M, Cottin Y, Petit JM, et al. Early cardiovascular events in women with a history of gestational diabetes mellitus. Cardiovasc Diabetol. 2016;15:15.

18. Daly B, Toulis KA, Thomas N, Gokhale K, Martin J, Webber J, et al. Increased risk of ischemic heart disease, hypertension, and type 2 diabetes in women with previous gestational diabetes mellitus, a target group in general practice for preventive interventions: a population-based cohort study. PLoS Med. 2018;15(1):e1002488.

19. Gagnon C, Magliano DJ, Ebeling PR, Dunstan DW, Zimmet PZ, Shaw JE, et al. Association between hyperglycaemia and fracture risk in non-diabetic middle-aged and older Australians: a national, population-based prospective study (AusDiab). Osteoporosis international : a journal established as result of cooperation between the European Foundation for Osteoporosis and the National Osteoporosis Foundation of the USA. 2010;21(12):2067-74.

20. Chauhan SP, Grobman WA, Gherman RA, Chauhan VB, Chang G, Magann EF, et al. Suspicion and treatment of the macrosomic fetus: a review. Am J Obstet Gynecol. 2005;193(2):332-46.

21. Yang G-R, Dye TD, Li D. Effects of pre-gestational diabetes mellitus and gestational diabetes mellitus on macrosomia and birth defects in upstate New York. Diabetes Res Clin Pract. 2019;155:107811.

22. Ghassibe-Sabbagh M, Mehanna Z, Abi Farraj L, Salloum AK, Zalloua PA. Gestational diabetes mellitus and macrosomia predispose to diabetes in the Lebanese population. Journal of clinical \& translational endocrinology. 2019; 16:100185.

23. James-Todd TM, Karumanchi SA, Hibert EL, Mason SM, Vadnais MA, Hu FB, et al. Peer reviewed: gestational age, infant birth weight, and subsequent risk of type 2 diabetes in mothers: nurses' health study II. Prev Chronic Dis. 2013;10.

24. Friedman S, Rabinerson D, Bar J, Erman A, Hod M, Kaplan B, et al. Microalbuminuria following gestational diabetes. Acta Obstet Gynecol Scand. 1995;74(5):356-60.

25. Kim C, Cheng YJ, Beckles GL. Cardiovascular disease risk profiles in women with histories of gestational diabetes but without current diabetes. Obstet Gynecol. 2008;112(4):875.

26. Bomback AS, Rekhtman Y, Whaley-Connell AT, Kshirsagar AV, Sowers JR, Chen $\mathrm{S}-\mathrm{C}$, et al. Gestational diabetes mellitus alone in the absence of subsequent diabetes is associated with microalbuminuria: results from the kidney early evaluation program (KEEP). Diabetes Care. 2010;33(12):2586-91.

27. Beharier O, Shoham-Vardi I, Pariente G, Sergienko R, Kessous R, Baumfeld Y, et al. Gestational diabetes mellitus is a significant risk factor for long-term maternal renal disease. The Journal of Clinical Endocrinology \& Metabolism. 2015;100(4):1412-6.

28. Kew S, Swaminathan B, Hanley AJ, Connelly PW, Sermer M, Zinman B, et al. Postpartum microalbuminuria after gestational diabetes: the impact of current glucose tolerance status. The Journal of Clinical Endocrinology \& Metabolism. 2015;100(3):1130-6.

29. Rawal S, Olsen SF, Grunnet LG, Ma RC, Hinkle SN, Granström C, et al. Gestational diabetes mellitus and renal function: a prospective study with 9-to 16-year follow-up after pregnancy. Diabetes Care. 2018:41(7): 1378-84.

30. Dehmer EW, Phadnis MA, Gunderson EP, Lewis CE, Bibbins-Domingo K, Engel SM, et al. Association between gestational diabetes and incident 
maternal CKD: the coronary artery risk development in young adults (CARD IA) study. Am J Kidney Dis. 2018;71(1):112-22.

31. Barrett PM, McCarthy FP, Kublickiene K, Cormican S, Judge C, Evans M, et al. Adverse pregnancy outcomes and long-term maternal kidney disease: a systematic review and meta-analysis. JAMA Network Open. 2020;3(2): e1920964-e.

32. Azizi F, Ghanbarian A, Momenan AA, Hadaegh F, Mirmiran P, Hedayati M, et al. Prevention of non-communicable disease in a population in nutrition transition: Tehran lipid and glucose study phase II. Trials. 2009;10(1):5.

33. Hogg RJ, Furth S, Lemley KV, Portman R, Schwartz GJ, Coresh J, et al. National Kidney Foundation's kidney disease outcomes quality initiative clinical practice guidelines for chronic kidney disease in children and adolescents: evaluation, classification, and stratification. Pediatrics. 2003; 111(6):1416-21.

34. Levey AS, Stevens LA, Schmid CH, Zhang Y, Castro AF III, Feldman HI, et al. A new equation to estimate glomerular filtration rate. Ann Intern Med. 2009;150(9):604-12.

35. AZIZI F, Khalili D, Aghajani H, ESTEGHAMATI A, Hosseinpanah F, DELAVARI A, et al. Appropriate waist circumference cut-off points among Iranian adults: the first report of the Iranian National Committee of obesity. 2010

36. Austin PC. An introduction to propensity score methods for reducing the effects of confounding in observational studies. Multivar Behav Res. 2011; 46(3):399-424.

37. Morken NH, Halland F, DeRoo L, Wilcox A, Skjærven R. Offspring birthweight by gestational age and parental cardiovascular mortality: a populationbased cohort study. BJOG Int J Obstet Gynaecol. 2018;125(3):336-41.

38. Usta A, Usta CS, Yildiz A, Ozcaglayan R, Dalkiran ES, Savkli A, et al. Frequency of fetal macrosomia and the associated risk factors in pregnancies without gestational diabetes mellitus. The Pan African Medical Journal. 2017;26.

39. Ong KK, Diderholm B, Salzano G, Wingate D, Hughes IA, MacDougall J, et al. Pregnancy insulin, glucose, and BMI contribute to birth outcomes in nondiabetic mothers. Diabetes Care. 2008:31(11):2193-7.

40. Zabetian A, Hadaegh F, Azizi F. Prevalence of metabolic syndrome in Iranian adult population, concordance between the IDF with the ATPIII and the WHO definitions. Diabetes Res Clin Pract. 2007;77(2):251-7.

41. Shankar A, Sun L, Klein BE, Lee KE, Muntner P, Javier FN, et al. Markers of inflammation predict the long-term risk of developing chronic kidney disease: a population-based cohort study. Kidney Int. 2011;80(11):1231-8.

42. Hamsten A, Walldius G, Szamosi A, Blombäck M, Faire U, Dahlén G, et al. Plasminogen activator inhibitor in plasma: risk factor for recurrent myocardial infarction. Lancet. 1987;330(8549):3-9.

43. Udeanu M, Guizzardi G, Di Pasquale G, Marchetti A, Romani F, Dalmastri V, et al. Relationship between coronary artery disease and C-reactive protein levels in NSTEMI patients with renal dysfunction: a retrospective study. BMC Nephrol. 2014;15(1):152.

44. Jenny NS, Tracy RP, Ogg MS, Luong LA, Kuller LH, Arnold AM, et al. In the elderly, interleukin-6 plasma levels and the-174G>C polymorphism are associated with the development of cardiovascular disease. Arterioscler Thromb Vasc Biol. 2002;22(12):2066-71.

45. Di Cianni G, Lencioni C, Volpe L, Ghio A, Cuccuru I, Pellegrini G, et al. Creactive protein and metabolic syndrome in women with previous gestational diabetes. Diabetes Metab Res Rev. 2007;23(2):135-40.

46. Heitritter SM, Solomon CG, Mitchell GF, Skali-Ounis N, Seely EW. Subclinica inflammation and vascular dysfunction in women with previous gestational diabetes mellitus. The Journal of Clinical Endocrinology \& Metabolism. 2005; 90(7):3983-8.

47. Winzer C, Wagner O, Festa A, Schneider B, Roden M, Bancher-Todesca D, et al. Plasma adiponectin, insulin sensitivity, and subclinical inflammation in women with prior gestational diabetes mellitus. Diabetes Care. 2004;27(7): $1721-7$.

48. Seliger SL, Salimi S, Pierre V, Giffuni J, Katzel L, Parsa A. Microvascular endothelial dysfunction is associated with albuminuria and CKD in older adults. BMC Nephrol. 2016;17(1):82.

49. Hu J, Norman M, Wallensteen M, Gennser G. Increased large arterial stiffness and impaired acetylcholine induced skin vasodilatation in women with previous gestational diabetes mellitus. BJOG Int J Obstet Gynaecol. 1998; 105(12):1279-87.

50. Anastasiou E, Lekakis JP, Alevizaki M, Papamichael CM, Megas J, Souvatzoglou A, et al. Impaired endothelium-dependent vasodilatation in women with previous gestational diabetes. Diabetes Care. 1998;21(12): $2111-5$.
51. Knock GA, McCarthy AL, Lowy C, Poston L. Association of gestational diabetes with abnormal maternal vascular endothelial function. BJOG Int J Obstet Gynaecol. 1997;104(2):229-34.

52. Roth GA, Johnson C, Abajobir A, Abd-Allah F, Abera SF, Abyu G, et al. Global, regional, and national burden of cardiovascular diseases for 10 causes, 1990 to 2015. J Am Coll Cardiol. 2017;70(1):1-25.

53. Garofalo C, Borrelli S, Minutolo R, Chiodini P, De Nicola L, Conte G. A systematic review and meta-analysis suggests obesity predicts onset of chronic kidney disease in the general population. Kidney Int. 2017;91(5): $1224-35$.

\section{Publisher's Note}

Springer Nature remains neutral with regard to jurisdictional claims in published maps and institutional affiliations.
Ready to submit your research? Choose BMC and benefit from:

- fast, convenient online submission

- thorough peer review by experienced researchers in your field

- rapid publication on acceptance

- support for research data, including large and complex data types

- gold Open Access which fosters wider collaboration and increased citations

- maximum visibility for your research: over $100 \mathrm{M}$ website views per year

At BMC, research is always in progress.

Learn more biomedcentral.com/submissions 